\title{
The differential effect of Toxoplasma gondii infection on the stability of BCL2-family members involves multiple activities
}

\author{
John Cherrington Carmen ${ }^{\dagger}$ and Anthony Peter Sinai* \\ Department of Microbiology, Immunology, and Molecular Genetics, University of Kentucky College of Medicine, Lexington, KY, USA
}

\section{Edited by:}

Rey Carabeo, Imperial College London,

UK

\section{Reviewed by:}

Peter J. Bradley, University of California Los Angeles, USA

Gustavo Arrizabalaga, University of Idaho, USA

${ }^{*}$ Correspondence:

Anthony Peter Sinai, Department of Microbiology, Immunology, and

Molecular Genetics, University of

Kentucky College of Medicine, 800

Rose Street, Lexington, KY 40536,

USA.

e-mail: sinai@uky.edu

${ }^{\dagger}$ Current address:

John Cherrington Carmen, Department of Pediatrics, University of Wisconsin

Medical School, University of

Wisconsin Hospitals and Clinics,

Madison, WI 53792, USA.
The regulation of mitochondrial permeability, a key event in the initiation of apoptosis is governed by the opposing actions of the pro-and anti-apoptotic members of the BCL2-family of proteins. The BCL2-family can be classified further based on the number of BCL-homology (BH) domains they encode. Pathogen mediated modulation of BCL2-family members play a significant role in their ability to affect the apoptotic pathways in the infected host cell. The protozoan parasite Toxoplasma gondii establishes a profound blockade of apoptosis noted by a requirement for host NFKB activity and correlating with the selective degradation of pro-apoptotic BCL2-family members. In this study, we explore the potential activities associated with the inherent stability of the anti-apoptotic BCL2 as well as the selective degradation of the pro-apoptotic proteins $B A X, B A D$, and BID. We find that multiple activities govern the relative stability of BCL2-family members suggesting a complex and balanced network of stability-enhancing and-destabilizing activities are perturbed by parasite infection. The data leave open the possibility for both parasite induced host activities as well as the direct consequence of parasite effectors in governing the relative levels of BCL2-proteins in the course of infection.

\section{Keywords: Toxoplasma gondii, BCL2, apoptosis, NFkB, proteasome, protease inhibition}

\section{INTRODUCTION}

The protozoan parasite Toxoplasma gondii is an important opportunistic infection in immune compromised individuals and a significant cause of birth defects when congenitally acquired (Tenter et al., 2000). As an obligate intracellular pathogen, T. gondii has successfully adapted to the intracellular environment (Boyle and Radke, 2009). In doing so the parasite has evolved complex mechanisms to interfere with or neutralize normal host defenses (Boothroyd, 2009). Among these is the apoptotic cascade which we and others have shown is profoundly inhibited in parasite infected cells (reviewed in Carmen and Sinai, 2007). The inhibition of apoptosis is connected with the ability of $T$. gondii to manipulate the NFKB pathway evidenced by the fact that the blockade of apoptosis is lifted in NFkB (RelA/p65-/-) knock out cells (Payne et al., 2003). While critically important, not all the anti-apoptotic events surrounding the blockade are channeled through NFKB as we recently demonstrated with regard to the parasite mediated inhibition of JNK activation in HeLa cells (Carmen et al., 2008).

The role of mitochondria in the activation of apoptosis is well documented (Pinkoski et al., 2006; Wang and Youle, 2009). The key triggering event committing a cell to apoptosis is the release of cytochrome $c$ from the mitochondria inter-membrane space (Goldstein et al., 2000; Gogvadze et al., 2006) resulting in the formation of the apoptosome (Zou et al., 1999). The recruitment and activation of the caspases in the apoptosome initiates the systematic dismantling of the cell due to targeted degradation of critical caspase substrates (Abu-Qare and Abou-Donia, 2001; Baliga and Kumar, 2003). The release of cytochrome $c$ is therefore under tight regulatory control.
Much of this control is mediated by the opposing actions of the anti-apoptotic and pro-apoptotic members of the BCL2-family of proteins (Scorrano and Korsmeyer, 2003; Brunelle and Letai, 2009). These proteins are classified based on their activity and the number of BCL2-homology (BH) domains (reviewed in Thomadaki and Scorilas, 2008; Brunelle and Letai, 2009). Accordingly the antiapoptotic BCL2 contains four BH domains (BH1, 2, 3, 4; Liston et al., 2003). Among the pro-apoptotic members are the multidomain protein (BAX, containing BH1, 2, 3; Lalier et al., 2007) and the $\mathrm{BH} 3$ only proteins BAD and BID (Marsden and Strasser, 2003). The anti-apoptotic BCL2 actively interferes with permeabilization of the mitochondrial outer membrane (MOM) by the multidomain proteins (e.g., BAX) thus blocking apoptosis (Thomadaki and Scorilas, 2008; Brunelle and Letai, 2009). Displacement of the protective $\mathrm{BCL} 2$ from $\mathrm{BAX}$ is mediated by members of the $\mathrm{BH} 3$ only sub-family thus promoting apoptosis (Thomadaki and Scorilas, 2008; Brunelle and Letai, 2009). Although controversial, BH3 only proteins may exert their effect additionally by the direct activation of BAX (Wu and Deng, 2002). Regardless of the mechanism of action, $\mathrm{BH} 3$ only proteins shift the balance toward a pro-apoptotic state. This stringent and nuanced level of control over the release of cytochrome $c$ is susceptible to pathogen manipulation.

Manipulation of the BCL2-family has been observed for viral (Galluzzi et al., 2008), bacterial (Faherty and Maurelli, 2008), and protozoan pathogens (Carmen and Sinai, 2007). The consequence of this manipulation is to either promote or inhibit apoptosis, resulting in an outcome that is advantageous to the specific pathogen. Our earlier work demonstrated that infection of mammalian 
cells by $T$. gondii results in the selective degradation of pro-apoptotic BCL2-family members (BAD, BAX) while the anti-apoptotic BCL2protein remained relatively unaffected (Carmen et al., 2006). With this study we investigate the contribution of $\mathrm{NF \kappa B}$, a key player in the parasite enforced blockade of apoptosis (Payne et al., 2003; Carmen and Sinai, 2007), as well as the roles of specific classes of proteolytic activities (Otlewski et al., 2005) on the selective parasite induced degradation. The results indicate that multiple activities target the specific proteins to ensure their stability. The data further suggest the differential stability profiles in response to infection may be due to both the direct impact of parasite activities as well the induction of host cell activities. In addition to increasing our understanding of the molecular basis for the T. gondii enforced block of apoptosis, additional insights into the biology of the BCL2family of proteins are revealed.

\section{MATERIALS AND METHODS CELL AND PARASITE MAINTENANCE}

Wild type mouse embryonic fibroblasts [WT MEF (line WT-1)] and the NFKB p65-/- mouse embryonic fibroblast line RelA-2 (Gapuzan et al., 2005), graciously provided by Dr. Alexander Hoffmann (University of California, San Diego), were maintained in $\alpha$-minimal essential medium ( $\alpha$-MEM) supplemented with 100 units $\mathrm{ml}^{-1}$ penicillin, $100 \mu \mathrm{g} \mathrm{ml}^{-1}$ streptomycin, $7 \%$ heatinactivated fetal bovine serum and $2 \mathrm{mM}$ L-glutamine (Gibco Invitrogen, Carlsbad, CA, USA). The RH strain of T. gondii with a deletion in the hypoxanthine-xanthine-guanine-phosphoribosyltransferase (HXGPRT) gene (Donald and Roos, 1998) was used in these experiments (NIH AIDS Research and Reference Program). Parasites were maintained by serial passage in Vero cells as described previously (Payne et al., 2003).

\section{ANALYSIS OF THE EFFECT OF T. GONDII INFECTION ON BCL2, BAX, BAD, AND BID LEVELS}

The effect of infection on the levels of BCL2, BAX, BAD, and BID was determined in WT MEF or p65-/- (RelA-2) MEF (Gapuzan et al., 2005) infected with increasing numbers of parasites [multiplicity of infection $(\mathrm{MOI})=0,2,4,6,8$, or 10 tachyzoites per cell]. Cells were seeded into six-well dishes and incubated at $37^{\circ} \mathrm{C}$ for $8 \mathrm{~h}$. Prior to infection, T. gondii tachyzoites were harvested, washed with PBS, and counted. The parasites were diluted in complete $\alpha$-MEM, added to the six-well dishes, and the dishes were returned to a $37^{\circ} \mathrm{C}$ incubator for $20 \mathrm{~h}$. After this incubation, the cells were harvested, resuspended in 1.0\% Triton $\mathrm{x}-100$ in PBS and centrifuged at 10,000 rpm for $7 \mathrm{~min}$ to remove insoluble material. The total protein concentration of the resulting supernatant was determined using a BCA Protein Assay Kit (Pierce Biotechnology, Inc., Rockford, IL, USA) and equal amounts of total protein were resolved via SDS-PAGE on $12 \%$ gels and analyzed via immunoblot as described previously (Payne et al., 2003). Blocking of immunoblots was performed with $5 \%$ bovine serum albumin in phosphate buffered saline containing $0.2 \%$ Tween 20 . The antibodies used were: mouse monoclonal anti-BCL2 (1:500, Santa Cruz Biotechnology, Santa Cruz, CA, USA, sc-7382), mouse monoclonal anti-BAX (1:500, Santa Cruz Biotechnology, Santa Cruz, CA, USA, sc-7480), rabbit polyclonal anti-BAD (1:12,000, Stressgen Bioreagents, Ann Arbor, MI, USA, AAP-020), and rabbit polyclonal
anti-BID (1:4000, Santa Cruz Biotechnology, Santa Cruz, CA, USA, sc-11423). Blots were stripped and reprobed with an anti-calnexin antibody to verify equal protein loading as previously described (Carmen et al., 2008). Detection of reactive proteins was achieved using enhanced chemiluminescence (Pierce) recorded on X-ray film (Fuji) as previously described (Carmen et al., 2006).

\section{INHIBITION OF THE PROTEASOME AND SPECIFIC PROTEASE CLASSES}

Proteasome/protease inhibitor studies were performed using the following experimental design. Cells were seeded into six-well dishes and, after an 8-h incubation period, infected at the MOI described in the figure. Uninfected and infected cells were incubated with the various inhibitors for the last $8 \mathrm{~h}$ of a 24 -h infection period. At the end of inhibitor treatment, cells were harvested and analyzed using SDS-PAGE and immunoblotting. The role of the proteasome in T. gondii-dependent BCL2-family member degradation was determined by analyzing the levels of BCL2, BAX, BAD, and BID in cells treated with $20 \mu \mathrm{M}$ MG132. The MG132 stock solution was made in DMSO and an equal volume of the carrier was added to the untreated samples. The protease inhibitors E64d, leupeptin, and $N^{\alpha}$-tosyl-phenylalanyl chloromethyl ketone (TPCK) were used to experimentally determine the role of cysteine proteases (E64d) and the trypsin-like serine proteases (leupeptin) and chymotrypsin-like serine proteases (TPCK) in the T. gondii-dependent degradation of BCL2-family members. Leupeptin (Sigma Aldrich, Milwaukee, WI, USA, L2023) was dissolved in sterile distilled water and used at a final concentration of $10 \mu \mathrm{g} \mathrm{ml}^{-1}$ leupeptin in $\alpha$-MEM. TPCK (Sigma, Milwaukee, WI, USA, T4376) in DMSO was diluted in $\alpha$-MEM to a final working concentration of $10 \mu \mathrm{M}$. The E64d stock (Sigma Aldrich, Milwaukee, WI, USA, E8640) was dissolved in $50 \%$ methanol and diluted into the medium to a concentration of $100 \mu \mathrm{M}$. In experiments using inhibitors dissolved with solvents other than water, control cells were treated with $\alpha$-MEM containing an identical volume of the solvent as the inhibitor $\alpha$-MEM.

\section{DENSITOMETRIC ANALYSIS OF THE IMMUNOBLOTS AND DATA ANALYSIS}

Normalized protein levels were determined using densitometric analysis. This was performed using ImageJ software (National Institutes of Health, Bethesda, MD, USA) to calculate the integrated density of both the band of interest (BCL2, BAX, BAD, or BID) and the corresponding loading control band (calnexin). Multiple immunoblot exposures were scanned into digital files and opened using Image J software. The background was subtracted from the image using the subtract background function and the image was inverted. The membranes had been exposed to film for multiple lengths of time and the exposure judged to be in the linear range was quantitated. Normalized protein level values represent the integrated density value (IDV) of the band of interest divided by the integrated density of the loading control band (e.g., BCL2/calnexin). Finally, the resulting values for multiple experiments were averaged and the SD was calculated. Given the variability of the data the following considerations went into the exclusion of specific experiments. (1) The presence in any lane of a given experiment of a protein of interest/calnexin ratio $>2.5$ was typically due to a problem with the loading control (data not shown) and was therefore excluded. (2) Immunoblots with a high uneven background 
level impinging on bands of interest were also excluded. Using the criteria for exclusion a minimum of four independent experiments were recorded for a given condition. The specific number of experiments employed in the statistical analysis is indicated in the figure legend for each sample.

\section{STATISTICAL ANALYSES}

The IDV values comprising the ratio of exposure level of the protein of interest relative to calnexin were analyzed using the GraphPad Prism software program. The data are presented in a graphical form as the mean for the specific sample with the error bars corresponding to the SE of the mean. In addition, we performed One-way analysis of variance (ANOVA) tests using the Repeated Measures Test. The repeated measures test is ideal given the experimental design as matched subjects are used in each experimental replicate. Accordingly, the variance in the relative level of the specific protein is measured across the MOI range for the specific experimental parameter. Thus the significance of the trend across the MOI range can be established. The level of significance was set at a $p$-value of $<0.05$.

The repeated test ANOVA analyses for the effect of the inhibitors used (Figures 3-6) are noted in Table 1. In addition to the analysis of the specific trends, the Dunnett test, whereby pairwise comparisons of significance (set at $p<0.05$ ) are made for a given MOI relative to the uninfected control, was used. The MOI's meeting this criterion are marked with an asterisk in the figures.

Finally, we established a representational scale based on the relative sensitivity of the protein to infection-mediated degradation. This scale follows the trend of the mean relative protein level pointing to specific trend whether or not it is statistically significant at the established $p<0.05$ for the given data set. Accordingly proteins exhibiting degradation at a $\mathrm{MOI}=2$ or $4(+++)$ are highly sensitive, proteins for which the onset of degradation is at MOI -6 to 8 are moderately sensitive $(++)$ while those showing degradation at MOI $=10$ are deemed marginally sensitive $(+)$. Those proteins that fail to show any degradation based on the quantified results are insensitive to infection-mediated degradation (-; Table 1).

\section{RESULTS \\ DIFFERENTIAL SENSITIVITY OF BCL2-FAMILY MEMBERS TO INFECTION- MEDIATED DEGRADATION}

We previously reported that $T$. gondii infection induces the selective loss of pro-apoptotic BCL2-family proteins in an infectious dose dependent manner (Carmen et al., 2006). In addition, studies on host transcriptional changes in response to infection fail to explain the specific loss of pro-apoptotic BCL2-family proteins (Molestina et al., 2003). In order to rigorously address the phenotype we reexamined the apparent selective degradation of proapoptotic BCL2-proteins using the more quantitative approaches described in the material and method. In our analyses we examined the anti-apoptotic protein BCL2, the multi-domain pro-apoptotic member BAX, and two BH3-only pro-apoptotic proteins BAD and BID (Thomadaki and Scorilas, 2008). Analysis of this nature is subject to considerable variation from experiment to experiment. Applying a ratiometric approach addresses some of this variability. Specific criteria for the inclusion of data are summarized in the
Section "Materials and Methods." Notably, in addition to defining the mean and SE we performed repeated measures ANOVA comparing the levels of significance for the infection level dependent loss of specific BCL2-family proteins. In addition, significant differences were recorded in pairwise comparisons relative to uninfected controls.

Consistent with previously published work we report that increasing T. gondii infection levels (MOI from 2 to 10) results in differential impacts on the anti-apoptotic BCL2-protein and the pro-apoptotic proteins BAX, BAD, and BID (Carmen et al., 2006). The BCL2-protein remains largely stable in the face of infection (Figure 1A). In compiling data from multiple independent experiments this trends is validated with a small though statistically insignificant dip at the highest MOI (Figure 1B). Overall the degradation of BCL2 across the entire infection range (MOI) was found not be significant ( $p$-value 0.0899). In contrast the multi-domain proapoptotic BAX is highly susceptible to infection-mediated degradation as evidenced in the representative gel (Figure 1A) and from the compiled quantitative data which shows a significant reduction in BAX steady state levels with an MOI of 2 and 4 (Figures 1A,B; $p$-value $<0.0001)$. The $\mathrm{BH} 3$-only proteins $\mathrm{BAD}$ and $\mathrm{BID}$ exhibit an intermediate phenotype being moderately sensitive (at MOI of 6-8) to infection-mediated degradation (Figures 1A,B; $p$-values of 0.0265 and 0.0083 respectively).

\section{HOST NFKB ACTIVITY ALONE IS NOT THE BASIS OF THE DIFFERENTIAL STABILITY IN RESPONSE TO INFECTION}

Our previous studies have established NFKB as an important mediator of the parasite-blockade of apoptosis (Molestina et al., 2003; Payne et al., 2003). This relationship however is not universally applicable to all aspects of apoptosis as NFKB shows no involvement in the infection-mediated block of JNK activation a key event in UV induced apoptosis (Carmen et al., 2008). The availability of RelA/p65-/- fibroblasts (Gapuzan et al., 2005) allows us to directly investigate the role of the intact $\mathrm{NFKB}$ cascade on the parasite mediated degradation of BCL2-family proteins.

In the absence of $\mathrm{NFKB}$ activity we observe what appears to be increased sensitivity of BCL2 to infection-mediated degradation with some protein loss at an MOI of 6 (Figures 2A,B). However this difference was not seen to be statistically significant (Figure 2C, $p$-value 0.7071). Likewise, the apparent trend for the multi-domain member BAX was sustained relative to infection of WT MEF's (Figures $2 \mathrm{~A}-\mathrm{C}$ ). This trend was not found to be statistically significant ( $p$-value 0.1122 ). In contrast the $\mathrm{BH} 3$-only members $\mathrm{BAD}$ and BID exhibited some stabilization with appreciable degradation only at the highest MOI (Figures 2A-C). Overall the data indicate that the post transcriptional stability of BCL2-family members is not significantly regulated by NFKB dependent activities.

\section{INHIBITION OF PROTEASOMAL DEGRADATION SELECTIVELY IMPACTS THE BH3-ONLY FAMILY MEMBERS}

Proteasome mediated protein degradation is involved in the regulated turnover of diverse cellular proteins (Hoff et al., 2004). Proteins are targeted for degradation by their ubiquitination (Hoff et al., 2004). The drug MG132 is readily membrane permanent and irreversibly blocks the activity of the proteasome (Lee and Goldberg, 1998). We reasoned that treatment of infected cells using MG132 


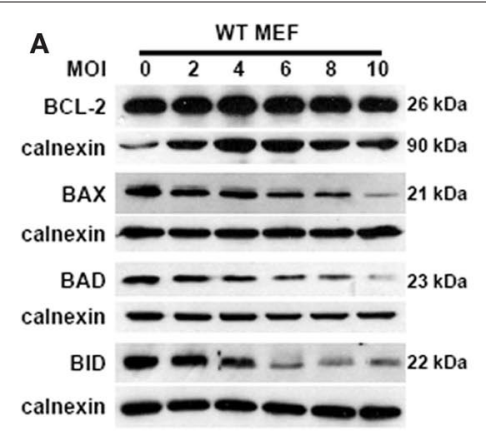

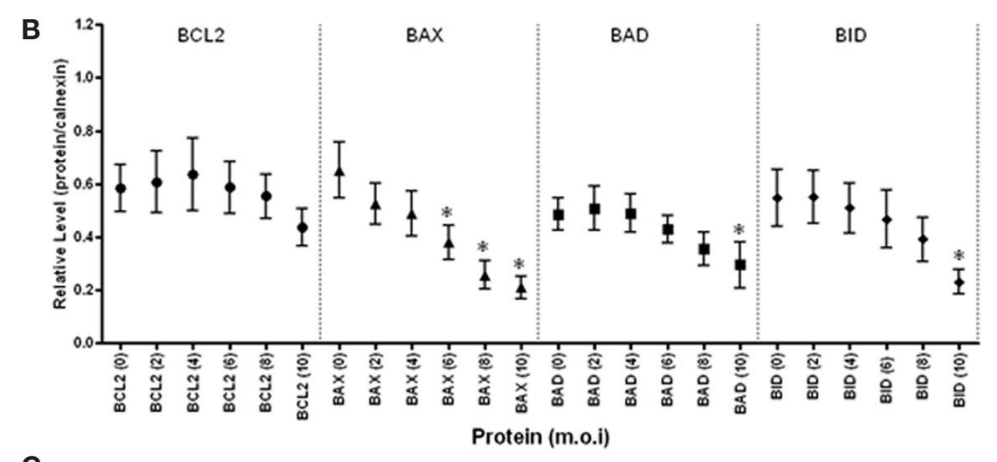

C

Repeated Measures ANOVA

\begin{tabular}{|c|c|c|c|}
\hline BCL2 & BAX & BAD & BID \\
\hline P value: 0.0899 & P value $<0.0001$ & P value: 0.0265 & P value: $\mathbf{0 . 0 0 8 3}$ \\
\hline ns & $* * *$ & $*$ & $* *$ \\
\hline
\end{tabular}

FIGURE 1 |The effect of Toxoplasma gondii infection on the steady state levels of the BCL2-family proteins in WT MEF. (A) Representative immunoblots detecting the levels of the anti-apoptotic BCL2, pro-apoptotic multi-domain member BAX and the BH3-only proteins BAD and BID in response to increasing infection (multiplicity of infection range 0 (uninfected) to 10). The signal for calnexin is used as a loading control. (B) Quantification of the relative levels of $\mathrm{BCL2}$-family proteins relative to the corresponding signal for calnexin in response to infection at a given $\mathrm{MOI}$. The multiplicity of infection for a given protein is denoted in the parenthesis following the name of the target protein. Using criteria outlined in the Section "Materials and Methods," the following number of independent experiments were used to assemble the presented data: BCL 2-8 experiments, BAX-10 experiments, BAD-8 experiments and BID-6 experiments. The error bars represent the SE of the mean (symbol). A single asterisk above an error bar signifies a significant data point relative to the uninfected control with a $p$-value $<0.05$ employing the Dunnett pairwise test. (C) Repeated measures ANOVA analysis relative to the uninfected control was performed. A p-value of 0.05 or higher were considered to be not significant (ns). Values of low significance $\left({ }^{*} 0.01-0.05\right)$, moderate significance $\left({ }^{* *} 0.001-0.01\right)$, highly significant $\left({ }^{* * *}<0.001\right)$ were used.

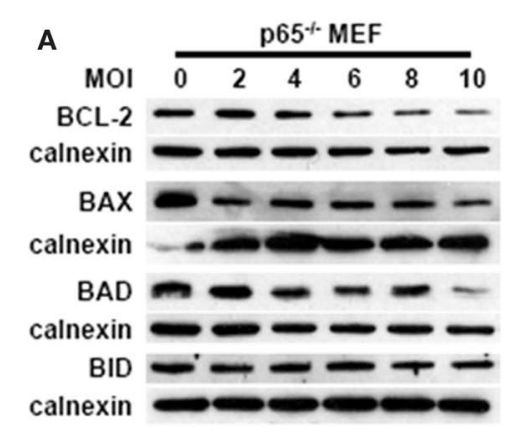

$\circ$

Repeated Measures ANOVA

\begin{tabular}{|c|c|c|c|}
\hline BCL2 & BAX & BAD & BID \\
\hline P value: 0.7071 & Pvalue: 0.1122 & Pvalue: $\mathbf{0 . 0 7 3 2}$ & P value: 0.0698 \\
\hline ns & ns & ns & ns \\
\hline
\end{tabular}

FIGURE 2 |The effect of Toxoplasma gondii infection on the steady state levels of the BCL2-family proteins in NFrB knock out fibroblasts (p65-/- MEF). (A) Representative immunoblots detecting the levels of the anti-apoptotic BCL2, pro-apoptotic multi-domain member BAX and the BH3-only proteins $B A D$ and $B I D$ in response to increasing infection [multiplicity of infection range $O$ (uninfected) to 10]. The signal for calnexin is used as a loading control. (B) Quantification of the relative levels of BCL2-family proteins relative to the corresponding signal for calnexin in response to infection at a given $\mathrm{MOI}$. The multiplicity of infection for a given protein is denoted in the parenthesis following the name of the target protein. Using criteria outlined in the Section "Materials and Methods," the following number of independent experiments were used to assemble the presented data: BCL2-5 experiments, BAX-4 experiments, BAD-4 experiments and BID-4 experiments. The error bars represent the SE of the mean (symbol). Specific data points with asterisk define a statistically significant difference $(p<0.05)$ in a pairwise test relative to the uninfected control. (C) Values for a repeated measures ANOVA across the MOI range for each protein indicates no significant overall change in NFKB deficient cells in response to infection. 
as described in Figure $\mathbf{3 A}$ would establish a role for proteasome mediated turnover of the BCL2-family proteins in response to infection. Our reasoning was that in the presence of the inhibitor steady state levels of the proteins would increase if proteasome-mediated turnover was responsible for the degradation of the specific protein. On account of the inherent variability in such experiments we conducted repeated measure ANOVA across the MOI range for the treated samples and their matched controls (Table 1).

The levels of none of the BCL2-family proteins were enhanced (higher relative levels at $\mathrm{MOI}=0$ ) in non-infected cells (Figures 3B,C). However, the steady state level for BID was markedly reduced in drug treated uninfected cells $(\mathrm{MOI}=0)$. This would suggest that a proteasome-sensitive stabilizing activity is involved in the normal turnover of BID (Figures 3B,C). Such a factor could be akin to a protease inhibitor, whose expression, turnover or activity could be impacted.

Interestingly, while MG132 failed to have any effect on the stability of BCL2 and BAX in response to infection, the capacity to degrade $\mathrm{BAD}$ and $\mathrm{BID}$ by the infection-mediated component was effectively lost (Figure 3C). This is noted in the essentially flat profile of the curve for MG132 treated BAD and BID cells (Figure 3C). MG132 is known to be an inhibitor of NFKB due to

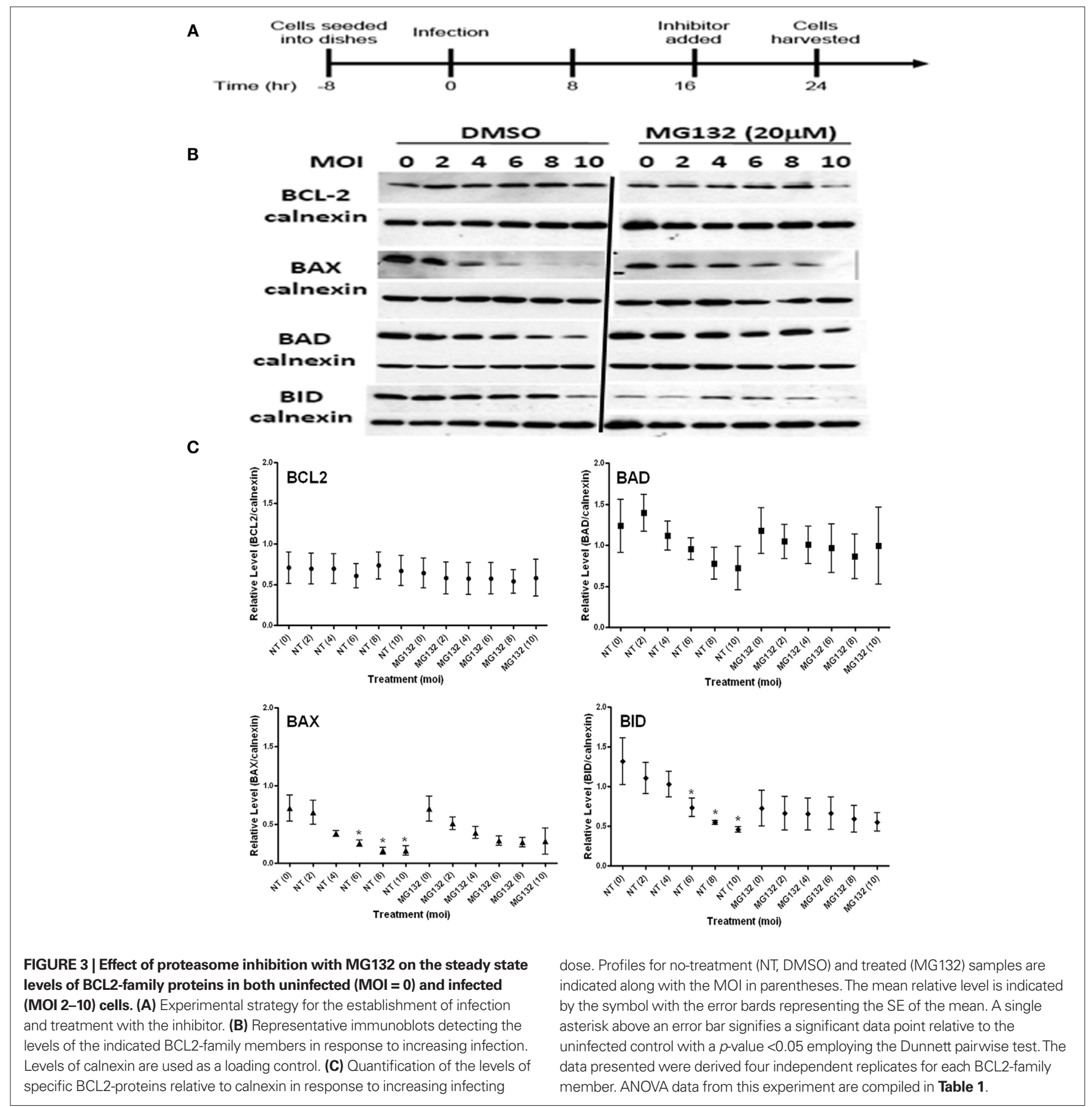


Table 1 | Impact of proteasome and protease inhibition on the stability of BCL2-family proteins in uninfected cells and in response to infection.

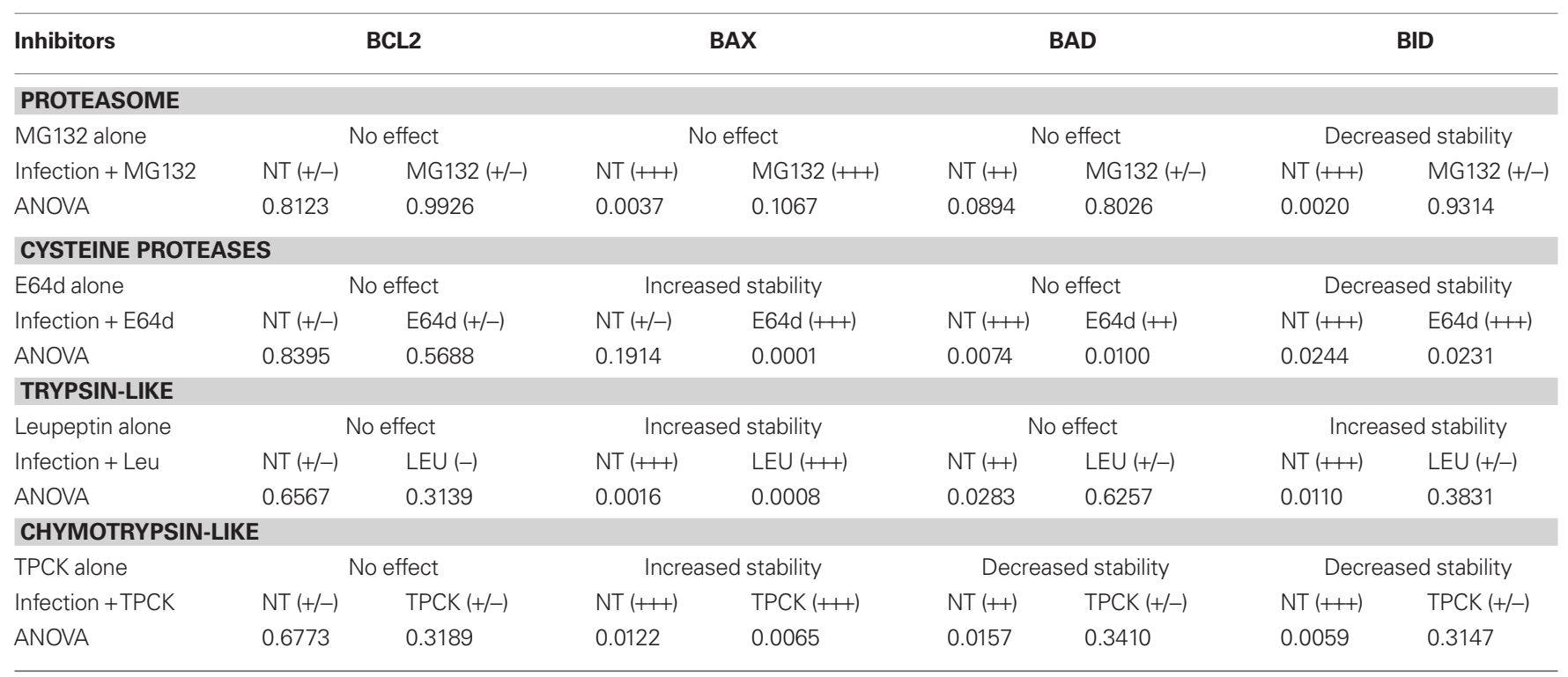

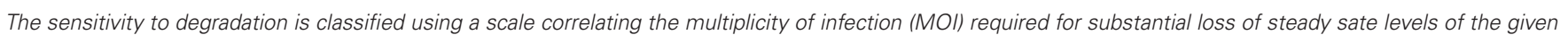

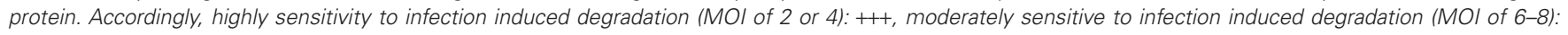

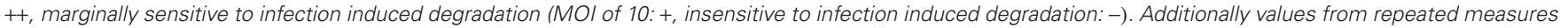
ANOVA are presented. p-Values $<0.05$ are considered significant. NT, no-treatment.

the block in the degradation of the ubiquitinated Phospho-IкB $\alpha$, the inhibitor of NFKB (Karin and Lin, 2002; Giuliano et al., 2003). It is therefore interesting that the pattern for infection-mediated degradation of BAD and BID follows a profile similar to that in infected RelA/p65-/- cells with the onset of degradation occurring at the highest MOI (Figure 2). This suggests that an NFKBregulated proteolytic activity is involved in the parasite-directed degradation of BH3-only proteins. Conversely enhanced stability of a protease inhibitor following proteasome inhibition could explain the absence of the infection-dependent degradation of these BH3 only proteins. The effects of MG132 on the parasite mediated degradation of BCL2-family proteins was subjected to ANOVA analysis. As reported in Table 1, MG132, resulted in the loss of infection-mediated degradation of BAD and BID with a similarly pronounced effect on BAX. BCL2 itself was unaffected when comparing the profiles for untreated and MG132 treated samples across the MOI range.

\section{CYSTEINE PROTEASES DIFFERENTIALLY IMPACT THE PRO-APOPTOTIC BCL2-FAMILY MEMBERS}

The membrane permeable cysteine protease inhibitor E64d (Hernandez and Roush, 2002; Lindvall, 2002) was used to establish the role of this class of proteolytic activities in stability of BCL2family member. Inhibitor treatment using a regimen identical to that above (Figure 3A) indicates that the inhibition of cysteine proteases has no significant effect on BCL2 levels and causes a small increase in the stability of BAX in the absence of infection (MOI $=0$; Figures 4A,B). There was no effect on the inherent stability of $\mathrm{BAD}$; however, E64d treatment resulted in a marked reduction in steady state BID levels. The effect on BID mirrors that seen for MG132 (Figure 3). Interestingly, the infection-mediated degradation of all of the BCL2-family proteins, except for BAX, was largely unaffected by E64d treatment as the general patterns for infection-mediated BCL2 member degradation was similar in treated and untreated samples (Figure 4). For all but BAX, the ANOVA values are similar when comparing untreated (NT) to the E64d treated samples. In the case of BAX however E64d resulted in a highly significant loss of variability at all the MOI's examined (Figure 4B; Table 1).

\section{INHIBITION OF "TRYPSIN-LIKE" SERINE PROTEASES HAS DIFFERENTIAL EFFECTS ON BCL2-FAMILY MEMBERS}

Leupeptin is a broad spectrum membrane permeant inhibitor of trypsin-like serine protease activities (Kurinov and Harrison, 1996). Treatment of uninfected cells (MOI $=0$ ) with leupeptin using the strategy presented in Figure 3A resulted in no effect for BCL2, BAX, or BAD (Figure 5). In contrast the mean steady state level of the $\mathrm{BH} 3$-only protein BID was enhanced in the presence of leupeptin (Figure 5), although the error bars are pronounced. These data would suggest that normal turnover of BID is mediated by a trypsin-like activity which, when inhibited, results in the accumulation of the protein in uninfected cells.

We examined the effect of leupeptin on the infection-mediated degradation of the BCL2-family proteins. While not affecting the levels in BCL2 in uninfected cells, levels of the protein trended in an upward direction with increasing infection (Figure 5). This upward trend, however, was not statistically significant based on ANOVA analysis (Table 1). There was no effect on the infectiondependent degradation of BAX (Figure 5; Table 1). In contrast, in the presence of leupeptin the infection-mediated degradation of $\mathrm{BAD}$ was reduced, with the protein becoming marginally sensitive to degradation (Figure 5; Table 1). Interestingly the marked 


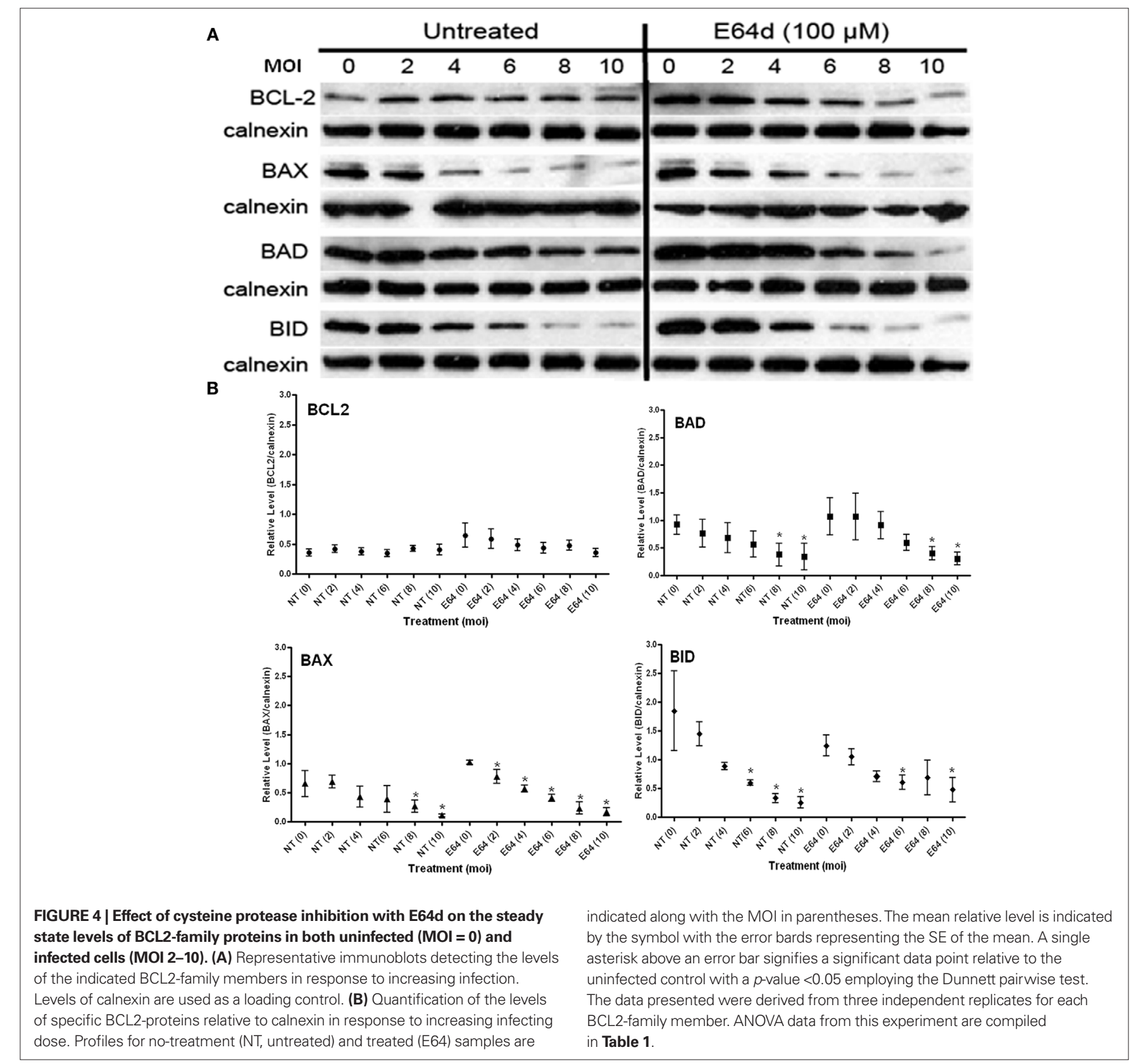

reduction in variability of $\mathrm{BAD}$ levels was seen only for this protein in the presence of leupeptin. This phenotype is exactly the opposite to what was observed for BID, where steady state levels were seen to become, highly variable on account of leupeptin. Furthermore, the effect of leupeptin in increasing the steady state levels of BID in uninfected cells, did have an impact on the infection-mediated turnover as that effect was blunted (ANOVA $p$-value 0.011 in untreated and 0.3831 in treated samples; Figure 5; Table 1). This indicates a distinct activity from that involved in the normal leupeptin-sensitive turnover of BID is present in the parasite infected cell. This could be either a host activity induced in the infected cell or a parasite derived activity secreted into the host cytoplasm.

\section{"CHYMOTRYPSIN-LIKE" SERINE PROTEASES DIFFERENTIALLY IMPACT PRO-APOPTOTIC BCL2-FAMILY MEMBERS}

The chymotrypsin-like proteases can be inhibited by TPCK (Frydrych and Mlejnek, 2008). TPCK treatment of infected cells using the modality in Figure 3A indicates that BCL2 levels are not controlled by a chymotrypsin -like serine protease (Figure 6; Table 1). In contrast, treatment of uninfected cells $(\mathrm{MOI}=0)$ with TPCK resulted in the accumulation of the multi-domain family member BAX (Figure 6; Table 1) but reduced levels of both the BH3-only proteins BAD and BAX (Figure 6). Furthermore, levels of BAD were fount to be quite variable. This differential effect on the pro-apoptotic BCL2-family suggests that chymotrypsin-like activities may degrade BAX directly. The reduced steady state levels 


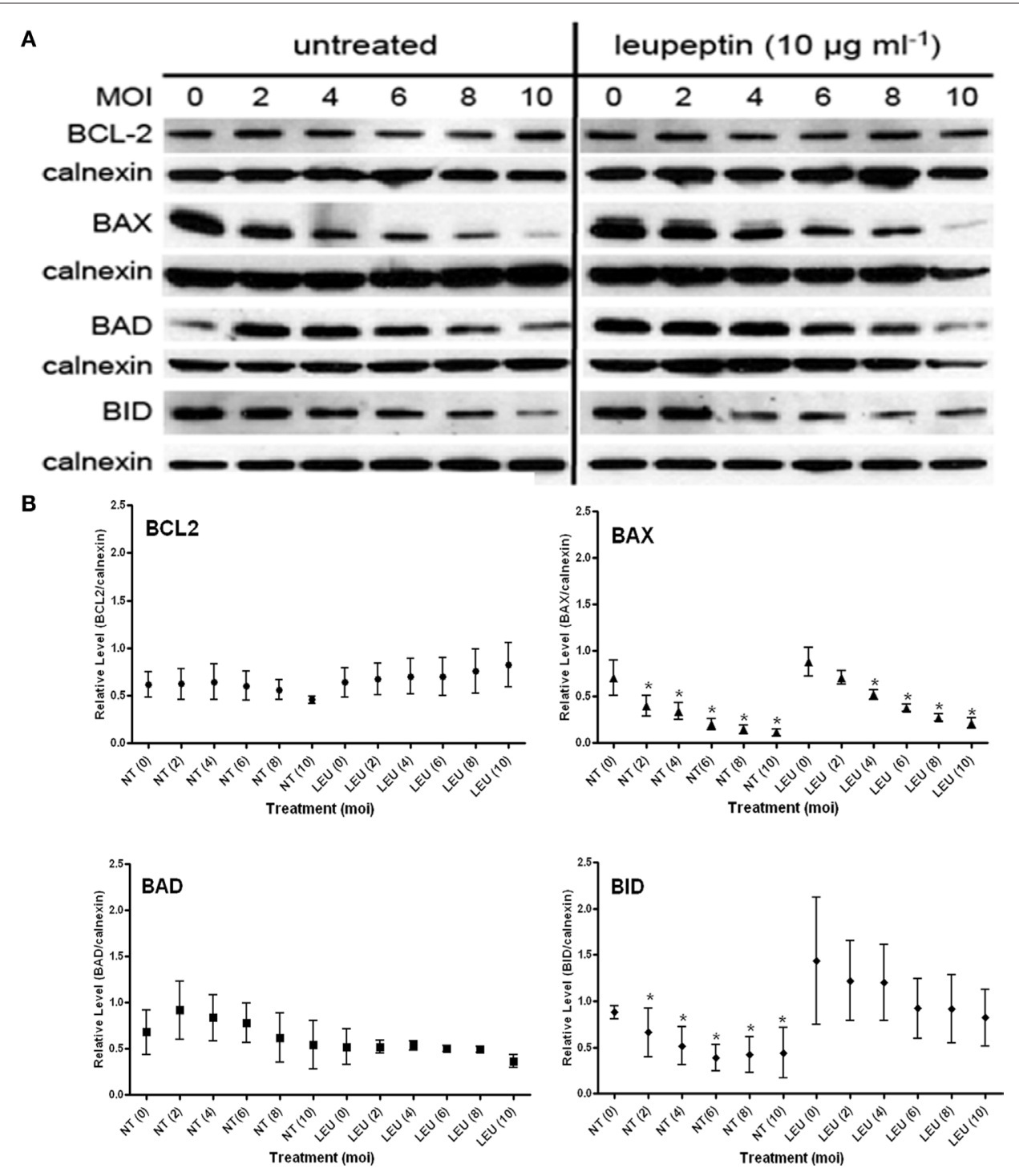

FIGURE 5 | Effect of trypsin-like serine protease inhibition with leupeptin on the steady state levels of BCL2-family proteins in both uninfected ( $\mathbf{M O I}=\mathbf{0}$ ) and infected cells (MOI 2-10). (A) Representative immunoblots detecting the levels of the indicated BCL2-family members in response to increasing infection. Levels of calnexin are used as a loading control.

(B) Quantification of the levels of specific BCL2-proteins relative to calnexin in response to increasing infecting dose. Profiles for no-treatment (NT, untreated) and treated (Leu) samples are indicated along with the $\mathrm{MOI}$ in parentheses. The mean relative level is indicated by the symbol with the error bards representing the SE of the mean. A single asterisk above an error bar signifies a significant data point relative to the uninfected control with a $p$-value $<0.05$ employing the Dunnett pairwise test. The data presented were derived from four independent replicates for each BCL2, BAX, BID, and untreated BAD samples. Three independent experiments were used for the BAD immunoblots with leupeptin treatment. ANOVA data from this experiment are compiled in Table $\mathbf{1}$. of both $\mathrm{BH} 3$ only proteins suggest an indirect effect where the inhibition of TPCK may result in the stabilization of a degradative activity with a distinct inhibitor profile.

Chymotrypsin-like serine protease activities do not appear to play a role in the infection-mediated turnover of BCL2 or BAX. However the activities associated with the infection-mediated degradation of the $\mathrm{BH} 3$-only proteins BAD and BID are inhibited as evident from the slope of the curves in response to the increasing infection dose. This trend is validated by the ANOVA data indicating a marked loss of variability in levels of these proteins due to infection (Table 1). Thus we can conclude that the infection-mediated degradation of the $\mathrm{BH} 3$-only proteins involves serine protease activities (both trypsin- and chymotrypsin-like) that may be induced in response to the infection or be secreted directly by the parasite.

\section{DISCUSSION}

The key triggering event in the induction of apoptosis along the intrinsic pathway is the release of cytochrome $c$ from mitochondria resulting in the activation of the initiator and eventually executioner caspases (Pinkoski et al., 2006; Wang and Youle, 2009). The caspases systematically and irreversibly dismantle key activities ensuring the 

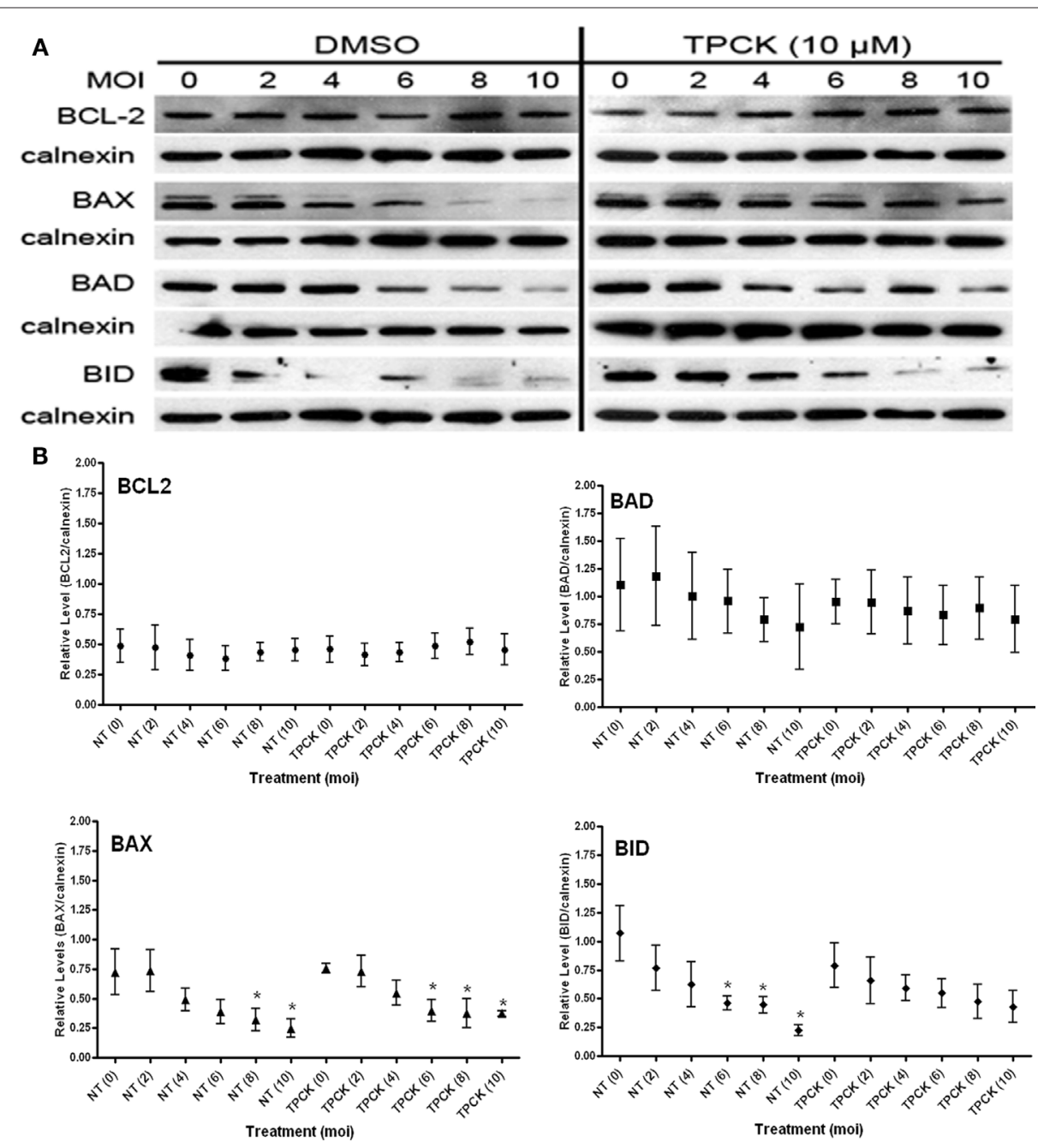

FIGURE 6 | Effect of chymotrypsin-like serine protease inhibition with TPCK on the steady state levels of BCL2-family proteins in both uninfected (MOI $=\mathbf{0}$ ) and infected cells (MOI 2-10). (A) Representative immunoblots detecting the levels of the indicated BCL2-family members in response to increasing infection. Levels of calnexin are used as a loading control. (B) Quantification of the levels of specific BCL2-proteins relative to calnexin in response to increasing infecting dose. Profiles for no-treatment (NT, untreated) and treated (TPCK) samples are indicated along with the $\mathrm{MOI}$ in parentheses. The mean relative level is indicated by the symbol with the error bards representing the SE of the mean. A single asterisk above an error bar signifies a significant data point relative to the uninfected control with a $p$-value $<0.05$ employing the Dunnett pairwise test. The data presented were derived from five independent replicates for BCL2, BAD, and BID. Five independent replicates were used for untreated BAX samples while four were included for the TPCK treated condition. ANOVA data from this experiment are compiled in Table 1. progression to an apoptotic death. Given the finality of cell death, cytochrome $c$ release is under tight regulation (Goldstein et al., 2000; Gogvadze et al., 2006). The pro- and anti-apoptotic arms of the BCL2-family proteins govern the balance of activities ensuring maintenance of cell viability or committing it to an apoptotic death (Scorrano and Korsmeyer, 2003; Brunelle and Letai, 2009). The BCL2-family is defined by the presence of the BH domains. The anti-apoptotic protein BCL2 possesses BH1, 2, 3, and 4 (Liston et al., 2003). Among the pro-apoptotic proteins BAX is a multidomain (BH1, 2,3) protein (Lalier et al., 2007) while both BAD and BID possess only the BH3 domain (Marsden and Strasser, 2003). In multicellular organisms, apoptosis provides an effective defense mechanisms against pathogen attack by sacrificing an infected cell thus controlling the pathogens capacity to replicate(Hasnain et al., 2003). As a countermeasure, pathogens have evolved elaborate mechanism to disrupt the apoptotic response (Barry and Beaman, 2006; Carmen and Sinai, 2007; Faherty and Maurelli, 2008; Galluzzi et al., 2008).

As an obligate intracellular parasite, T. gondii is critically dependent on its ability to block apoptosis (Carmen and Sinai, 2007). This blockade is established at multiple levels involving the transmission of an apoptotic signal, the triggering of the apoptogenic response and finally its execution. Our studies have firmly established a vital role for the transcription factor NFKB in the establishment of the overall apoptotic stage (Molestina et al., 2003; Payne et al., 2003; Molestina and Sinai, 2005a,b). However the role of NFKBmediated effects is not universal when examining how the parasite impacts specific components in the apoptotic process. Accordingly, 
while the inhibition of caspase activity is completely dependent on $\mathrm{NF} \kappa \mathrm{B}$-regulated components, the infection-mediated inhibition of JNK-kinases following UV irradiation is independent of it (Carmen et al., 2006, 2008) despite evidence for considerable crosstalk between the NFKB and JNK pathways (Papa et al., 2006; Wullaert et al., 2006). The complexity of the response is further evident in the differential response of BCL2-family proteins to infection as seen in multiple studies. As a whole, multiple studies demonstrate that $T$. gondii infection shifts the balance of BCL2-proteins to favor an anti-apoptotic state (Goebel et al., 2001; Carmen et al., 2006; Hippe et al., 2009a,b). This shift is evident from the selective degradation of pro-apoptotic BCL2-family proteins and the relative resistance to degradation of the anti-apoptotic members (Carmen et al., 2006). A pathogen mediated selective degradation of pro-apoptotic BCL2-family proteins has also been reported in Chlamydia infected cells (Zhong et al., 2001; Dong et al., 2005; Ying et al., 2005). The phenotype of infection-dependent degradation may be connected to the parasite strain as others, using an avirulent Type II isolate fail to observe this phenotype (Hippe et al., 2009b). In their study, they point out that in the absence of quantification in our prior work the degradation phenotype was not delineated (Hippe et al., 2009a). We chose to delve deeper into the potential mechanistic basis of this response by investigating the involvement of NFKB-mediated regulation as well as the selective inhibition of specific classes of proteases. We further examine the response quantitatively and confirm that the selective degradation of proapoptotic BCL2-family members does in fact occur in response to Toxoplasma infection and present potential mechanisms for what is a complex phenotype.

The steady state level of any protein is governed by the balance of its inherent stability and its rate of synthesis. In pilot studies we blocked de novo protein synthesis using cycloheximide and monitored the levels of BCL2-family proteins over time. These studies indicate a half life for BCL2 of around $6 \mathrm{~h}$ while that of BAD and BID was $>8 \mathrm{~h}$ (data not shown). Interestingly, the multi-domain protein BAX exhibited a half life of around $2 \mathrm{~h}$ suggesting a relatively high turnover (data not shown). This relative instability is reflected in the fact that BAX was found to be the most susceptible to infection-mediated degradation (Figure 1). Notably, the rates of degradation in response to infection for the $\mathrm{BH} 3$ only proteins BAD and BID exhibited moderate sensitivity (MOI 6-8; Figure 1). The anti-apoptotic BCL2-protein, which possesses $\mathrm{BH} 1,2,3$ and BH4 domains was inherently resistant to degradation (Figure 1) suggestive of a protective effect derived from the $\mathrm{BH} 4$ domain and/ or the increased expression as suggested from the transcriptional data (Molestina et al., 2003 and data not shown). Together the spectrum of responses is consistent with a complex network of activities at play.

The role of NFKB in the regulation of the apoptotic cascade is well documented (Karin and Lin, 2002). Transcriptional data on infected cells indicates that the anti-apoptotic proteins BCL2 and BFL1 are upregulated with BFL1 induction being strongly dependent on NFKB (Molestina et al., 2003). In contrast infection fails to have any transcriptional consequence on the pro-apoptotic proteins (Molestina et al., 2003 and data not shown). Interestingly, while BAX degradation was unchanged in RelA/p65-/- MEF's the stability of BCL2 was compromised while that of the $\mathrm{BH} 3$ only proteins BAD and BID enhanced (Figure 2). Taken together the data suggest that NFKB differentially impact the different classes of BCL2-family of proteins during infection and that the trends correlate with a role for NFKB in establishing the anti-apoptotic state along the BCL2-family axis. It further suggests that multiple activities, potentially defined by the class of specific protein being targeted, governs its stability in the course of infection.

Protein turnover is governed by the activities of distinct degradative mechanisms including the proteasome and a spectrum of proteases. We used well established membrane permeant inhibitors of the proteasome (MG132), cysteine proteases (E64d), and serine proteases: including trypsin-like proteases (leupeptin) and chymotrypsin-like proteases (TPCK), to evaluate the impact on the stability of the BCL2-family proteins in response to infection. The lack of availability of membrane permeant inhibitors of other protease classes precluded analysis of their impact in intact cells. The results which are summarized in Table 1 confirm the complexity of the networks governing turnover of these proteins in infected cells. The data in Table 1 represents a summary of the information presented in the figures dealing with the inhibition studies (Figures 3-6).

Our basic rationale was that the inhibition of a proteolytic activity would result in the accumulation of a target protein. In contrast, a reduction in the steady state level of a target protein following treatment with an inhibitor would suggest that the specific target may be an inhibitory, and therefore stabilizing activity. Thus loss of a protease inhibitor would increase steady state turnover, reducing the levels of the target protein. As evident in Table 1, the consequence of a specific inhibitor on the steady state level ( $\mathrm{MOI}=0$, i.e., in the absence of infection) is to increase stability, increase turnover or have no effect. Notably the stability of BCL2 was unaffected by any of the inhibitors used (Table 1). Furthermore, BAX, which was subject to the highest turnover, was stabilized by the inhibition of all the non-proteasome mediated degradation mechanisms. The results with the $\mathrm{BH} 3$-only proteins $\mathrm{BAD}$ and BID failed to follow an obvious pattern except in the case of chymotrypsin-like activities (inhibited by TPCK) where decreased inherent stability was observed (Table 1). All the other treatments failed to significantly impact steady state levels while clearly affecting the inherent stability of BID (Table 1). The increased turnover of BID as a result of the inhibition of the proteasome, cysteine proteases, and chymotrypsin-like activities suggest the loss of a stabilizing activity. In contrast, the increased steady state levels of BID in the presence of leupeptin implicate trypsin-like activity in the normal turnover of BID (Figure 5). The effect of the proteasome and protease inhibitors on the infection-mediated stability of the BCL2-family proteins further establishes the relative insensitivity of BCL2 to infection-mediated degradation. To the contrary, a trend indicating an infection level dependent accumulation of BCL2 in the presence of leupeptin suggests a trypsin-like activity is specifically involved (Figure 5).

None of the inhibitors had any effect on the infection-mediated degradation of BAX (Table 1), despite the non-proteasome inhibitors increasing the stability the protein in the absence of infection (Table 1). As a result, although the initial levels of BAX were typically higher, their degradation was evident at the lower multiplicities of infection (Figures 3-6). The greatest impact on 
infection-mediated stability was seen with the $\mathrm{BH} 3$-only proteins BAD and BID (Table 1). Judging from the slope of the curves, the inhibition of the proteasome effectively blocked the parasite mediated degradation in response to infection level (Figure 3C). This general trend is followed for leupeptin treatment (trypsin-like activities) where for BID the apparent decreases of the mean intensity are neutralized by the significant SE (Figure 5B). This pattern repeats for both BAD and BID following TPCK (chymotrypsin-like activities) treatment (Figure 6B). The cysteine protease inhibitor E64d had a minor effect in stabilizing BAD requiring a higher infection dose to observe degradation (Figure 4).

A central question and unresolved question presented by this work is that of the source of the specific proteolytic and/or protective activities involved. What is clear is that multiple activities broadly focused on the class of the BCL2-family protein are involved. In the case of the relative stability of BCL2 in response to infection the data suggest a role for a "protective" activity that is at least partially regulated by $\mathrm{NF \kappa B}$. This suggests an indirect mechanism where the parasite is modulating host gene expression to sustain BCL2 levels by the combined action of increased transcription (Molestina et al., 2003) and the potential induction of a protective activity. In this regard the identification of an NFKB induced serpin (serine protease inhibitor) that targets the serine protease family activities are intriguing (Dechend et al., 1999; Mutoh et al., 2008; Jerczynska and Pawlowska, 2009). The observation that leupeptin completely abolishes infection-dependent BCL2 degradation at the highest MOI is consistent with this conclusion (Figure 4).

Multiple proteolytic activities are involved in the degradation of the pro-apoptotic BCL2-proteins. The insensitivity of BAX degradation in response to any of the inhibitors used suggests the involvement of a distinct activity. Infection could induce the activity (by activation of a protease or elimination of an inhibitor) in the host cell or be the consequence of a secreted parasite protease.

In the case of the $\mathrm{BH} 3$ only proteins $\mathrm{BAD}$ and $\mathrm{BID}$ the capacity for infection-mediated degradation is dampened or lost by the inhibition of the proteasome (Figure 3) as well as both trypsinand chymotrypsin-like activities (Figures 5 and 6). The loss of degradation following proteasome inhibition implicates a ubiquitin mediated turnover in the parasite induced degradation. This would suggest a mechanism that is indirectly impacted by parasite infection. In contrast, the effects of leupeptin and TPCK could be explained by the activation of a host protease, or loss of an inhibitory activity. Both trypsin and chymotrypsin are serine proteases and are therefore potentially inhibitable by the serpin class of endogenous serine protease inhibitors (Law et al., 2006). In addition the delivery of a specific parasite protease into the host cytoplasm cannot be ruled out. Such an activity has been described for the intravacuolar bacteria of the Chlamydia species which release CPAF (Chlamydia

\section{REFERENCES}

Abu-Qare, A. W., and Abou-Donia, M. B. (2001). Biomarkers of apoptosis: release of cytochrome $c$, activation of caspase-3, induction of 8-hydroxy-2'-deoxyguanosine, increased 3-nitrotyrosine, and alteration of p53 gene. J. Toxicol. Environ. Health B Crit. Rev. 4, 313-332.
Ahn, H. J., Song, K. J., Son, E. S., Shin, J. C., and Nam, H.W. (2001). Protease activity and host cell binding of the $42-\mathrm{kDa}$ rhoptry protein from Toxoplasma gondii after secretion. Biochem. Biophys. Res. Commun. 287, 630-635.

Baliga, B., and Kumar, S. (2003). Apaf-1/ cytochrome $c$ apoptosome: an essential initiator of caspase activation or

protease/proteasome-like activity factor) into the cytoplasm of the host cell where they selectively target $\mathrm{BH} 3$ only proteins (Zhong et al., 2001; Byrne and Ojcius, 2004; Dong et al., 2004; Fischer et al., 2004; Ying et al., 2005). Chlamydial CPAF additionally is inhibited by the proteasome inhibitor MG132 (Zhong et al., 2001; Byrne and Ojcius, 2004) an inhibition profile consistent with what we observe for T. gondii infection-mediated degradation specifically of BH3only proteins (Table 1). The availability of the T. gondii genome (www.toxodb.org) allows for the identification of potential CPAFhomologs in this parasite that shares several features regarding the establishment of its intracellular niche with Chlamydiae (Sinai and Joiner, 1997). Of note the T. gondii genome encodes several secreted proteases and serpins which have been shown to be secreted into the parasitophorous vacuole but not into the host cell (Ahn et al., 2001; Morris et al., 2002; Teo et al., 2007; Cuppari et al., 2008).

A growing body of work reveals that the efficient targeting of cellular components by parasite effectors directly influences cellular functions (Boyle and Radke, 2009). Our work with the PVMlocalized I $\kappa B$ kinase activity (Molestina and Sinai, 2005a,b), the work with the ROP-family kinases (reviewed in Peixoto et al., 2010) and a rhoptry derived phosphatase (Gilbert et al., 2007) delivered to the host nucleus all point to a highly refined system for host manipulation. Notably, among the proteins found in the rhoptry proteome are predicted proteases and peptidases (Bradley et al., 2005) which could be delivered to the host cell like the ROP kinases. This study presents potential targets that are directly linked into the establishment of the replication permissive niche by enforcing the anti-apoptotic state. Recent advances in generating targeted gene disruptions in the parasite (Fox et al., 2009; Huynh and Carruthers, 2009) may allow the direct consequence of the elimination of secreted proteases on the stability of the BCL-family of proteins.

In conclusion, our data support a body of evidence that the inhibition of apoptosis by $T$. gondii is the manifestation of a complex reprogramming of the host cell. The systems employed to enforce this blockade are multi-factorial and dynamic. While some parasite effectors, directly targeting host cell proteins have been identified the potential for novel activities including potentially proteases reveals a new weapon in the arms race that defines the pathogen host interaction.

\section{ACKNOWLEDGMENTS}

The authors thank the members of the Sinai laboratory for valuable discussions. This work was supported by grant number RO1AI49367 awarded to Anthony Peter Sinai from the NIH. John Cherrington Carmen was supported by an NIH Training Grant T32AI 49795 and a Dissertation Year Fellowship from the University of Kentucky. Neither author has any conflicts of interest pertaining to the publication of this work.

just a sideshow? Cell Death Differ. 10, 16-18.

Barry, D. P., and Beaman, B. L. (2006). Modulation of eukaryotic cell apoptosis by members of the bacterial order Actinomycetales. Apoptosis 11, 1695-1707.

Boothroyd, J. C. (2009). Toxoplasma gondii: 25 years and 25 major advances for the field. Int. J. Parasitol. 39, 935-946.

Boyle, J. P., and Radke, J. R. (2009). A history of studies that examine the interactions of toxoplasma with its host cell: emphasis on in vitro models. Int. J. Parasitol. 39, 903-914.

Bradley, P. J., Ward, C., Cheng, S. J., Alexander,D. L., Coller, S., Coombs, 
G. H., Dunn, J. D., Ferguson, D. J., Sanderson, S. J., Wastling, J. M., and Boothroyd,J.C. (2005). Proteomic analysis of rhoptry organelles reveals many novel constituents for host-parasite interactions in Toxoplasma gondii. J. Biol. Chem. 280, 34245-34258.

Brunelle, J. K., and Letai, A. (2009). Control of mitochondrial apoptosis by the Bcl-2 family. J. Cell. Sci. 122, 437-441.

Byrne, G. I., and Ojcius, D. M. (2004). Chlamydia and apoptosis: life and death decisions of an intracellular pathogen. Nat. Rev. Microbiol. 2, 802-808.

Carmen, J. C., Hardi, L., and Sinai, A. P. (2006). Toxoplasma gondii inhibits ultraviolet light-induced apoptosis through multiple interactions with the mitochondrion-dependent programmed cell death pathway. Cell. Microbiol. 8, 301-315.

Carmen, J. C., and Sinai, A. P. (2007). Suicide prevention: disruption of apoptotic pathways by protozoan parasites. Mol. Microbiol. 64, 904-916.

Carmen, J. C., Southard, R. C., and Sinai, A. P. (2008). The complexity of signaling in host-pathogen interactions revealed by the Toxoplasma gondii-dependent modulation of JNK phosphorylation. Exp. Cell Res. 314, 3724-3736.

Cuppari, A. F., Sanchez, V., Ledesma, B., Frank, F. M., Goldman, A., Angel, S. O., and Martin, V. (2008). Toxoplasma gondiiprotease inhibitor-1 (TgPI-1) is a novel vaccine candidate against toxoplasmosis. Vaccine 26, 5040-5045.

Dechend, R., Maass, M., Gieffers, J., Dietz, R., Scheidereit, C., Leutz, A., and Gulba, D. C. (1999). Chlamydia pneumoniae infection of vascular smooth muscle and endothelial cells activates NF-kappaB and induces tissue factor and PAI-1 expression: a potential link to accelerated arteriosclerosis. Circulation 100, 1369-1373.

Donald, R. G., and Roos, D. S. (1998). Gene knock-outs and allelic replacements in Toxoplasmagondii: HXGPRT as a selectable marker for hit-and-run mutagenesis. Mol. Biochem. Parasitol. 91, 295-305.

Dong, F., Pirbhai, M., Xiao, Y., Zhong, Y., Wu, Y., and Zhong, G. (2005). Degradation of the proapoptotic proteins Bik, Puma, and Bim with Bcl-2 domain 3 homology in Chlamydia trachomatis-infected cells. Infect. Immun. 73, 1861-1864.

Dong, F., Su, H., Huang, Y., Zhong, Y., and Zhong, G. (2004). Cleavage of host keratin 8 by a Chlamydia-secreted protease. Infect. Immun. 72, 3863-3868.

Faherty, C. S., and Maurelli, A. T. (2008). Staying alive: bacterial inhibition of apoptosis during infection. Trends Microbiol. 16, 173-180.

Fischer, S. F., Vier, J., Kirschnek, S., Klos, A., Hess, S., Ying, S., and Hacker, G. (2004). Chlamydia inhibit host cell apoptosis by degradation of proapoptotic BH3-only proteins. J. Exp. Med. 200, 905-916.

Fox, B. A., Ristuccia, J. G., Gigley, J. P., and Bzik, D. J. (2009). Efficient gene replacements in Toxoplasma gondii strains deficient for nonhomologous end joining. Eukaryotic Cell 8, 520-529.

Frydrych, I., and Mlejnek, P. (2008). Serine protease inhibitors $N$-alpha-tosyl-Llysinyl-chloromethylketone (TLCK) and $\mathrm{N}$-tosyl-L-phenylalaninylchloromethylketone (TPCK) are potent inhibitors of activated caspase proteases. J. Cell. Biochem. 103, 1646-1656.

Galluzzi, L., Brenner, C., Morselli, E., Touat, Z., and Kroemer, G. (2008). Viral control of mitochondrial apoptosis. PLoS Pathog. 4, e1000018. doi: 10.1371/journal.ppat. 1000018

Gapuzan, M. E., Schmah, O., Pollock, A. D., Hoffmann, A., and Gilmore, T. D. (2005). Immortalized fibroblasts from NF-kappaB RelA knockout mice show phenotypic heterogeneity and maintain increased sensitivity to tumor necrosis factor alpha after transformation by v-Ras. Oncogene 24, 6574-6583.

Gilbert, L. A., Ravindran, S., Turetzky, J. M., Boothroyd, J. C., and Bradley. P. J. (2007). Toxoplasma gondii targets a protein phosphatase $2 \mathrm{C}$ to the nuclei of infected host cells. Eukaryotic Cell 6, 73-83.

Giuliano, M., A. D’Anneo, A. De Blasio, Vento, R., and Tesoriere, G. (2003). Apoptosis meets proteasome, an invaluable therapeutic target of anticancer drugs. Ital. J. Biochem. 52, 112-121.

Goebel, S., Gross, U., and Luder, C. G. (2001). Inhibition of host cell apoptosis by Toxoplasma gondii is accompanied by reduced activation of the caspase cascade and alterations of poly(ADP-ribose) polymerase expression. J. Cell. Sci. 114, 3495-3505.

Gogvadze, V., Orrenius, S., and Zhivotovsky, B. (2006). Multiple pathways of cytochrome $c$ release from mitochondria in apoptosis. Biochim. Biophys. Acta 1757, 639-647.

Goldstein, J. C., Waterhouse, N. J., Juin, P., Evan, G. I., and Green, D. R. (2000). The coordinate release of cytochrome $c$ during apoptosis is rapid, complete and kinetically invariant. Nat. Cell Biol. 2, 156-162.

Hasnain, S. E., Begum, R., Ramaiah, K. V., Sahdev, S., Shajil, E. M., Taneja, T. K., Mohan, M., Athar, M., Sah,
N. K., and Krishnaveni, M. (2003). Host-pathogen interactions during apoptosis. J. Biosci. 28, 349-358.

Hernandez, A. A., and Roush, W. R. (2002). Recent advances in the synthesis, design and selection of cysteine protease inhibitors. Curr. Opin. Chem. Biol. 6, 459-465.

Hippe, D., Gais, A., Gross, U., and Luder, C. G. (2009a). Modulation of caspase activation by Toxoplasma gondii. Methods Mol. Biol. 470, 275-288.

Hippe, D., Weber, A., Zhou, L., Chang, D. C., Hacker, G., and Luder, C. G. (2009b). Toxoplasma gondii infection confers resistance against BimSinduced apoptosis by preventing the activation and mitochondrial targeting of pro-apoptotic bax. J. Cell. Sci. 122, 3511-3521.

Hoff, H., Zhang, H., and Sell, C. (2004). Protein degradation via the proteasome. Methods Mol. Biol. 285, 79-92.

Huynh, M. H., and Carruthers, V. B. (2009). Tagging of endogenous genes in a Toxoplasma gondii strain lacking Ku80. Eukaryotic Cell 8, 530-539.

Jerczynska, H., and Pawlowska, Z. (2009). Intracellular signaling pathways involved in inhibition of PAI-1 expression by CNP in endothelial cells. Regul. Pept. 155, 150-155.

Karin, M., and Lin, A. (2002). NF-kappaB at the crossroads of life and death. Nat. Immunol. 3, 221-227.

Kurinov, I.V., and Harrison, R. W. (1996). Two crystal structures of the leupeptin-trypsin complex. Protein Sci. 5, 752-758.

Lalier, L., Cartron, P. F., Juin, P., Nedelkina, S., Manon, S., Bechinger, B., and Vallette, F. M. (2007). Bax activation and mitochondrial insertion during apoptosis. Apoptosis 12, 887-896.

Law, R. H., Zhang, Q., McGowan, S., Buckle, A. M., Silverman, G. A., Wong, W., Rosado, C. J., Langendorf, C. G., Pike, R. N., Bird, P. I., and Whisstock, J.C. (2006). An overview of the serpin superfamily. Genome Biol. 7, 216.

Lee, D. H., and Goldberg, A. L. (1998). Proteasome inhibitors: valuable new tools for cell biologists. Trends Cell Biol. 8, 397-403.

Lindvall, M. K. (2002). Molecular modeling in cysteine protease inhibitor design. Curr. Pharm. Des. 8 , 1673-1681.

Liston, P., Fong, W. G., and Korneluk. R. G. (2003). The inhibitors of apoptosis: there is more to life than $\mathrm{Bcl} 2$. Oncogene 22, 8568-8580.

Marsden, V. S., and Strasser, A. (2003). Control of apoptosis in the immune system: $\mathrm{Bcl}-2, \mathrm{BH} 3$-only proteins and more. Annu. Rev. Immunol. 21, 71-105.
Molestina, R. E., Payne, T. M., Coppens, I., and Sinai, A. P. (2003). Activation of NF-kappaB by Toxoplasma gondii correlates with increased expression of antiapoptotic genes and localization of phosphorylated IkappaB to the parasitophorous vacuole membrane. J. Cell. Sci. 116, 4359-4371.

Molestina, R. E., and Sinai, A. P. (2005a). Detection of a novel parasite kinase activity at the Toxoplasma gondii parasitophorous vacuole membrane capable of phosphorylating host IkappaBalpha. Cell. Microbiol. 7, 351-362.

Molestina, R. E., and Sinai, A. P. (2005b). Host and parasite-derived IKK activities direct distinct temporal phases of NF- $\{$ kappa $\}$ B activation and target gene expression following Toxoplasma gondii infection. J. Cell. Sci. 118, 5785-5796

Morris, M. T., Coppin, A., Tomavo, S., and Carruthers, V. B. (2002). Functional analysis of Toxoplasma gondii protease inhibitor 1. J. Biol. Chem. 277, 45259-45266.

Mutoh, M., Niho, N., Komiya, M., Takahashi, M., Ohtsubo, R., Nakatogawa, K., Ueda, K., Sugimura, T., and Wakabayashi, K. (2008). Plasminogen activator inhibitor-1 (Pai-1) blockers suppress intestinal polyp formation in Min mice. Carcinogenesis 29, 824-829.

Otlewski, J., Jelen, F., Zakrzewska, M., and Oleksy, A. (2005). The many faces of protease-protein inhibitor interaction. EMBO J. 24, 1303-1310.

Papa, S., Bubici, C., Zazzeroni, F., Pham, C. G., Kuntzen, C., Knabb, J. R., Dean, K., and Franzoso, G. (2006). The NF-kappaB-mediated control of the JNK cascade in the antagonism of programmed cell death in health and disease. Cell Death Differ. 13, 712-729.

Payne, T. M., Molestina, R. E., and Sinai, A. P. (2003). Inhibition of caspase activation and a requirement for NF-kappaB function in the Toxoplasma gondii-mediated blockade of host apoptosis. J. Cell. Sci. 116, 4345-4358.

Peixoto, L., Chen, F., Harb, O. S., Davis, P. H., Beiting, D. P., Brownback, C. S. Ouloguem, D., and Roos, D. S. (2010). Integrative genomic approaches highlight a family of parasite-specific kinases that regulate host responses. Cell Host Microbe 8, 208-218.

Pinkoski, M. J., Waterhouse, N. J., and Green, D. R. (2006). Mitochondria, apoptosis and autoimmunity. Curr. Dir. Autoimmun. 9, 55-73.

Scorrano, L., and Korsmeyer, S. J. (2003). Mechanisms of cytochrome crelease by proapoptotic BCL-2 family members. 
Biochem. Biophys. Res. Commun. 304, 437-444.

Sinai, A. P., and Joiner, K. A. (1997). Safe haven: the cell biology of nonfusogenic pathogen vacuoles. Annu. Rev. Microbiol. 51, 415-462.

Tenter,A.M., Heckeroth, A. R., and Weiss, L. M. (2000). Toxoplasma gondii: from animals to humans. Int. J. Parasitol.30, 1217-1258.

Teo, C. F., Zhou, X. W., Bogyo, M., and Carruthers, V. B. (2007). Cysteine protease inhibitors block Toxoplasma gondii microneme secretion and cell invasion. Antimicrob. Agents Chemother. 51, 679-688.

Thomadaki, H., and Scorilas, A. (2008). Molecular profile of the BCL2 family of the apoptosis related genes in breast cancer cells after treatment with cytotoxic/cytostatic drugs. Connect. Tissue Res. 49, 261-264.

Wang, C., and Youle, R. J. (2009). The role of mitochondria in apoptosis*. Annu. Rev. Genet. 43, 95-118.

Wu, X., and Deng, Y. (2002). Bax and $\mathrm{BH} 3$-domain-only proteins in p53mediated apoptosis. Front. Biosci. 7:d151-d156.

Wullaert, A., Heyninck, K., and Beyaert, R. (2006). Mechanisms of crosstalk between TNF-induced NF-kappaB and JNK activation in hepatocytes. Biochem. Pharmacol. 72, 1090-1101.

Ying, S., Seiffert, B. M., Hacker, G., and Fischer. S. F. (2005). Broad degradation of proapoptotic proteins with the conserved Bcl-2 homology domain 3 during infection with Chlamydia trachomatis. Infect. Immun. 73, 1399-1403.

Zhong, G., Fan, P., Ji, H., Dong, F., and Huang, Y. (2001). Identification of a chlamydial protease-like activity factor responsible for the degradation of host transcription factors. J. Exp. Med. 193, 935-942.

Zou, H.,Li, Y., Liu, X., and Wang, X. (1999). An APAF-1.cytochrome $c$ multimeric complex is a functional apoptosome that activates procaspase-9. J. Biol. Chem. 274, 11549-11556.

Conflict of Interest Statement: The authors declare that the research was conducted in the absence of any commercial or financial relationships that could be construed as a potential conflict of interest.
Received: 22 September 2010; accepted: 02 January 2011; published online: 24 January 2011.

Citation: Carmen JC and Sinai AP (2011) The differential effect of Toxoplasma gondii infection on the stability of BCL2family members involves multiple activities. Front. Microbio. 2:1. doi: 10.3389/ fmicb.2011.00001

This article was submitted to Frontiers in Cellular and Infection Microbiology, a specialty of Frontiers in Microbiology. Copyright (c) 2011 Carmen and Sinai. This is an open-access article subject to an exclusive license agreement between the authors and Frontiers Media SA, which permits unrestricted use, distribution, and reproduction in any medium, provided the original authors and source are credited. 